\title{
Cancer Molecular Evolution
}

\author{
David Posada ${ }^{1}$
}

Received: 10 August 2015/Accepted: 11 August 2015/Published online: 20 August 2015

(C) The Author(s) 2015. This article is published with open access at Springerlink.com

By far, the majority of studies in molecular evolution have focused on genetic change across one or more generations. Much less is known about the genetic changes that occur during the life time of an individual, or somatic evolution, of which cancer is probably the best-known example. Cancer is an adaptive evolutionary process in which distinct genetic clones compete for space and resources (Cairns 1975; Greaves and Maley 2012; Nowell 1976).

Modern cancer biology and genomics have validated the evolutionary nature of cancer, which has attracted much attention in recent years (Burrell and Swanton 2014; Gerlinger et al. 2014). Not surprisingly, cancer genomics has unveiled a significant amount of intratumor heterogeneity in most tumor types (Burrell et al. 2013; Michor and Polyak 2010; Swanton 2012). However, but logically, most studies in cancer genomics have been mostly concerned with the identification of the genetic and epigenetic changes that lead to cell transformation, tumor growth, metastasis and drug resistance, and much less with molecular evolutionary aspects. Despite a relatively rich literature on cancer evolutionary dynamics (Michor et al. 2004; Sottoriva et al. 2011), little is known about the evolutionary mechanisms that drive tumor progression at the molecular and cellular level, and evolutionary insights in cancer are based, for the most part, on mathematical models of carcinogenesis (Beerenwinkel et al. 2015).

Fortunately, the chance to obtain a more quantitative understanding of cancer molecular evolution is here.

David Posada

dposada@uvigo.es

1 Department of Biochemistry, Genetics and Immunology and Institute of Biomedical Research of Vigo (IBIV), University of Vigo, 36310 Vigo, Spain
Decreasing NGS costs and the already large amount of genomic data made available by the International Cancer Genome Consortium (https://dcc.icgc.org) or The Cancer Genome Atlas (http://cancergenome.nih.gov) should facilitate detailed studies on the molecular evolution of cancer. Still, the paramount opportunity for molecular evolutionary studies in cancer will be the one provided by single-cell genomics techniques (Wang and Navin 2015), which open wide the door for the application of the conceptual and analytical machinery of molecular evolution. In particular, population genomics and phylogenomics, which are mostly based on individualized data (e.g., DNA or protein sequences), will prove to be critical tools in this regard.

There are multiple fundamental questions in cancer that might be at least partially answered under a sound molecular evolution framework. For example, what are the relative roles of selection and genetic drift? While the presumption is that selection is the solely driving force in cancer, this might depend on the particular scenario (Sottoriva et al. 2015). In fact, estimates derived from mathematical model fitting suggest that the selective advantage of driver mutations can be as low as $0.4-1 \%$ (Beerenwinkel et al. 2007; Bozic et al. 2010). Basic parameterssuch as tumor effective population size, cell generation times or cell turnover-for understanding the role of genetic drift in cancer progression have not yet been formally measured (Merlo et al. 2006). Indeed, the characterization of the adaptation process and the role of neutrality have always been fundamental themes in molecular evolution (Lachance and Tishkoff 2013; Savolainen et al. 2013), and existing methods should be used to interrogate cancer genomic data.

In addition, statistical models of evolution will be useful in testing hypotheses about potentially different substitution processes acting in a tumor, or to measure tumoral 
evolutionary rates from genomic data. Relaxed molecular clocks could be utilized to estimate whether a metastasis was established early or late after transformation, or the temporal dynamics of tumor growth (see for example Zhao et al. 2014). Also, tumor genealogies could help in understanding tumor demographics in tempo and space, for example as typically done in viral epidemiology. Likewise, models of tumor growth including the cancer stem cell model (see Navin and Hicks 2010) could be formally compared under a phylogenetic framework using available statistical tests. Existing methods for the identification of convergent evolution might help to pinpoint new "driver genes”, particularly for non-coding regions. Moreover, ancestral character reconstruction techniques could be exploited to infer the genomic composition of the initial cell that originated a primary tumor or a metastasis, and the order of the different genomic events that took place. Major evolutionary aspects like the role and extent of tumor population structure, admixture, or different forms of gene flow-not just metastases but also the movement of cells within tumors, or into contiguous regions-currently not well understood, could also benefit from the use of standard tools in population genomics.

Indeed, somatic cancer evolution differs from germline evolution in fundamental ways (Sidow and Spies 2015). Most importantly, somatic evolution is asexual, proceeding through cell mitosis and therefore without chromosomal segregation or crossing over. The fact that the whole cancer genome is non-recombining implies that genetic hitchhiking and clonal interference should be common (see for example Neher 2013), but also that the variance of the different estimates from a single locus will be huge, so some care is need in this regard. Furthermore, all significant variations in cancer occur de novo in each individual-with the exception of a few transmissible cancersmeaning that the time scale and the level of divergence will be very narrow. Importantly, many parameter estimates or tests in molecular evolution assume neutrality, so the robustness of these methods to the presence of selection should be assessed before their application in cancer.

Understanding cancer evolution can have significant applications, such as more robust predictive biomarkers to improve personalized treatment and prevent drug resistance (Jamal-Hanjani et al. 2015; McGranahan and Swanton 2015). Evolutionary signatures such as clonal expansions or mutational diversity could help predicting cancer progression (Maley et al. 2006; Mengelbier et al. 2015; see also Neher et al. 2014). Evolutionary biology concepts and tools remain underused in cancer biology (Aktipis et al. 2011; Shibata 2012). The availability of genomic data, in particular that from single cells, should help change this.
Acknowledgments David Posada is supported by the European Research Council (ERC-617457- PHYLOCANCER) and participates in the BIOCAPS (Biomedical Capacities Support Program) initiative funded by the EU Seventh Framework Program (REGPOT 2012-2013-1).

Open Access This article is distributed under the terms of the Creative Commons Attribution 4.0 International License (http://crea tivecommons.org/licenses/by/4.0/), which permits unrestricted use, distribution, and reproduction in any medium, provided you give appropriate credit to the original author(s) and the source, provide a link to the Creative Commons license, and indicate if changes were made.

\section{References}

Aktipis CA, Kwan VS, Johnson KA, Neuberg SL, Maley CC (2011) Overlooking evolution: a systematic analysis of cancer relapse and therapeutic resistance research. PLoS One 6:e26100

Beerenwinkel N, Antal T, Dingli D, Traulsen A, Kinzler KW, Velculescu VE, Vogelstein B, Nowak MA (2007) Genetic progression and the waiting time to cancer. PLoS Comput Biol 3:e225

Beerenwinkel N, Schwarz RF, Gerstung M, Markowetz F (2015) Cancer evolution: mathematical models and computational inference. Syst Biol 64:e1

Bozic I, Antal T, Ohtsuki H, Carter H, Kim D, Chen S, Karchin R, Kinzler KW, Vogelstein B, Nowak MA (2010) Accumulation of driver and passenger mutations during tumor progression. Proc Natl Acad Sci USA 107:18545

Burrell RA, Swanton C (2014) Tumour heterogeneity and the evolution of polyclonal drug resistance. Mol Oncol 8:1095

Burrell RA, McGranahan N, Bartek J, Swanton C (2013) The causes and consequences of genetic heterogeneity in cancer evolution. Nature 501:338

Cairns J (1975) Mutation selection and the natural history of cancer. Nature 255:197

Gerlinger M, McGranahan N, Dewhurst SM, Burrell RA, Tomlinson I, Swanton C (2014) Cancer: evolution within a lifetime. Annu Rev Genet 48:215

Greaves M, Maley CC (2012) Clonal evolution in cancer. Nature 481:306

Jamal-Hanjani M, Quezada SA, Larkin J, Swanton C (2015) Translational implications of tumor heterogeneity. Clin Cancer Res 21:1258

Lachance J, Tishkoff SA (2013) Population genomics of human adaptation. Annu Rev Ecol Evol Syst 44:123

Maley CC, Galipeau PC, Finley JC, Wongsurawat VJ, Li X, Sanchez CA, Paulson TG, Blount PL, Risques RA, Rabinovitch PS, Reid BJ (2006) Genetic clonal diversity predicts progression to esophageal adenocarcinoma. Nat Genet 38:468

McGranahan N, Swanton C (2015) Biological and therapeutic impact of intratumor heterogeneity in cancer evolution. Cancer Cell 27:15

Mengelbier LH, Karlsson J, Lindgren D, Valind A, Lilljebjorn H, Jansson C, Bexell D, Braekeveldt N, Ameur A, Jonson T, Kultima HG, Isaksson A, Asmundsson J, Versteeg R, Rissler M, Fioretos T, Sandstedt B, Borjesson A, Backman T, Pal N, Ora I, Mayrhofer M, Gisselsson D (2015) Intratumoral genome diversity parallels progression and predicts outcome in pediatric cancer. Nat Commun 6:6125

Merlo LM, Pepper JW, Reid BJ, Maley CC (2006) Cancer as an evolutionary and ecological process. Nat Rev Cancer 6:924 
Michor F, Polyak K (2010) The origins and implications of intratumor heterogeneity. Cancer Prev Res 3:1361

Michor F, Iwasa Y, Nowak MA (2004) Dynamics of cancer progression. Nat Rev Cancer 4:197

Navin NE, Hicks J (2010) Tracing the tumor lineage. Mol Oncol 4:267

Neher RA (2013) Genetic draft, selective interference, and population genetics of rapid adaptation. Annu Rev Ecol Syst 44:195

Neher RA, Russell CA, Shraiman BI (2014) Predicting evolution from the shape of genealogical trees. eLife 3:e03568

Nowell PC (1976) The clonal evolution of tumor cell populations. Science 194:23

Savolainen O, Lascoux M, Merila J (2013) Ecological genomics of local adaptation. Nat Rev Genet 14:807

Shibata D (2012) Cancer. Heterogeneity and tumor history. Science 336:304

Sidow A, Spies N (2015) Concepts in solid tumor evolution. Trends Genet TIG 31:208
Sottoriva A, Vermeulen L, Tavare S (2011) Modeling evolutionary dynamics of epigenetic mutations in hierarchically organized tumors. PLoS Comput Biol 7:e1001132

Sottoriva A, Kang H, Ma Z, Graham TA, Salomon MP, Zhao J, Marjoram P, Siegmund K, Press MF, Shibata D, Curtis C (2015) A Big Bang model of human colorectal tumor growth. Nat Genet 47:209

Swanton C (2012) Intratumor heterogeneity: evolution through space and time. Cancer Res 72:4875

Wang Y, Navin NE (2015) Advances and applications of single-cell sequencing technologies. Mol Cell 58:598

Zhao J, Siegmund KD, Shibata D, Marjoram P (2014) Ancestral inference in tumors: how much can we know? J Theor Biol 359:136 